\title{
Simulation and Analysis of 3 Phase Multi-Level Inverter
}

\author{
Aprajita Rana \\ Delhi Technological \\ University, \\ Main Bawana Road, \\ New Delhi-110042
}

\author{
Himanshu Bansal \\ Delhi Technological \\ University, \\ Main Bawana Road, \\ New Delhi-110042
}

\author{
Ketan Lakhera \\ Delhi Technological \\ University, \\ Main Bawana Road, \\ New Delhi-110042
}

\author{
Ketan Sethi \\ Delhi Technological \\ University, \\ Main Bawana Road, \\ New Delhi-110042
}

\begin{abstract}
The aim of our present work is to obtain an output voltage using 3-phase multi-level inverter. An inverter is a device that converts the input DC voltage into output AC voltage. Here DC batteries are used as input supply and fed to the multilevel inverter. The multi-level inverter is achieved using cascaded H-bridge inverters. These $\mathrm{H}$-bridge inverters use mosfets as switches whose gating pulses are controlled by a microcontroller. This inverter also uses mosfets driver IC to convert TTL level signals into high current output signals.
\end{abstract}

\section{Keywords}

MOSFETS, ICL7667, Arduino Uno

\section{INTRODUCTION}

Inverter is a device that converts $\mathrm{DC}$ voltage to $\mathrm{AC}$ voltage. These devices are used as power backups in households and have a growing use in energy systems such as solar energy, hydro energy, etc. As these systems generate a DC output which needs to be converted to AC output to be consumed commercially.

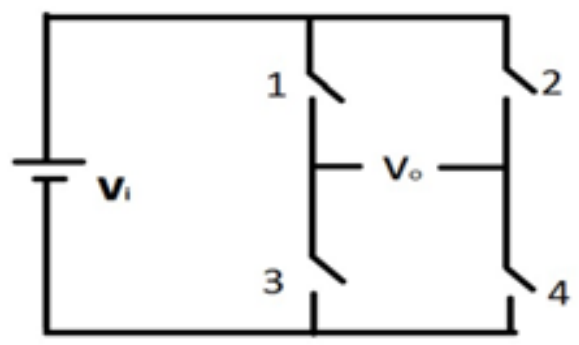

Fig 1: Basic H-bridge inverter

This is the basic inverter that uses 4 switches and converts a DC input wave into a square wave AC output. The basic problem with this configuration is presence of harmonics on its output side that leads to severe effect on the performance of the systems connected to them.

To avoid the effect of harmonics we use multilevel inverter. Multilevel inverters have advantages like minimum harmonic distortion; reduced EMI/RFI generation and can operate on several voltage levels.

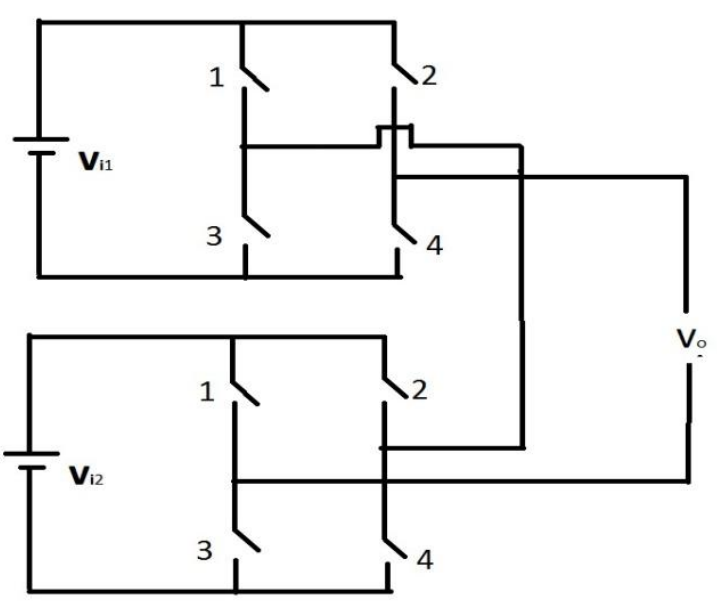

Fig 2: Multi-level Inverters

Multilevel inverters are three types.

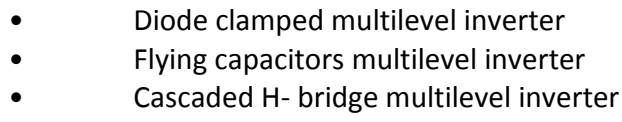

We will focus on the cascaded $\mathrm{H}$-bridge inverter as out of the three configurations. The cascaded H-bridge can be developed with more ease than others. In the above shown figure, two cascaded inverters are used to form a 3-level inverter.

\section{PROBLEM ADDRESSED}

The main function of the inverter is to convert the DC input that is a constant signal to an AC signal that is sine wave. This research paper shows the simulation of 3-phase 5-level inverter that takes the constant signal and converts it to a signal closer to sine wave and with increase in number of levels by cascading more $\mathrm{H}$-bridges; a proper sine wave could be achieved.

\section{HARDWARE USED}

The 3-phase 5-level inverter comprises of 24 mosfets , 12 mosfet driver IC and a DC source. Each phase of the inverter uses 8 mosfets and 4 mosfet driver IC. The gating signals of mosfets are provided by a microcontroller.

uses 8 mosfets and 4 mosfet driver IC. The gating signals of mosfets are provided by a microcontroller.

\subsection{ICL7667-Mosfets Driver IC}

The ICL7667 is a dual monolithic high-speed driver designed to convert TTL level signals into high current outputs at voltages up to $15 \mathrm{~V}$. With an output voltage a few millivolts less than the supply voltage and a maximum supply voltage of $15 \mathrm{~V}$, the ICL7667 is suitable for driving power mosfets in 
high frequency switched-mode power converters. The ICL7667's high current outputs reduce power losses in the power mosfets by rapidly charging and discharging the gate capacitance. It finds its application in switching power supplies, DC-DC converters and motor controllers.

\subsection{Microcontroller- Arduino Uno}

The Arduino Uno is a microcontroller board based on the ATmega328. It contains 14 digital input/output pins, 6 analog inputs, a USB connection, a $16 \mathrm{MHz}$ ceramic resonator, an ICSP header, a power jack, and a reset button. One need to power it with a AC-to-DC adapter or battery, connect it to a computer to get it started. In this project, Arduino Uno has been used to provide the switching pulses to mosfets and to power ICL7667.

\subsection{Mosfets}

The term MOSFETS stands for Metal Oxide Semiconductor Field Effect Transistor. It has four terminals i.e. source (S), gate $(\mathrm{G})$, drain (D), and body (B). Often the body terminal of the mosfets is connected to source terminal making it a three terminal device. It is a type of field effect transistor that works by varying the width of channel along which holes or electrons flow. The charge carriers enter at source and exit via drain. It is a voltage controlled device as width of the channel is controlled by voltage at gate. There are two modes in which a mosfets can work, depletion mode and enhancement mode. Power mosfets has high switching speed making it well suited for power electronics applications. The mosfets used in this project is IRFZ44N that is of $\mathrm{N}-$ Channel type.

\section{SOFTWARE}

Matlab - R2012b (Version 8.0)

We used the Simulink tool in Matlab to obtain simulation of the inverter. We obtained the desired output, which could be observed in the scope on Matlab , and those output are provided below.

\section{WORKING}

Here, we worked on a 5-level inverter that is formed using 2 single $\mathrm{H}$-bridge inverters connected in series whose mosfets are fired at different time intervals to generate 5-levels of voltage.

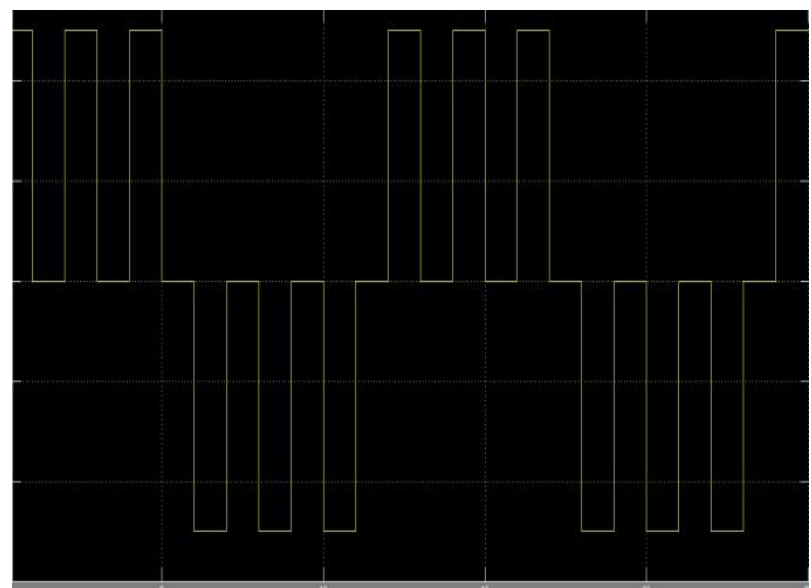

Fig 3.Waveform of 1st H-bridge inverter

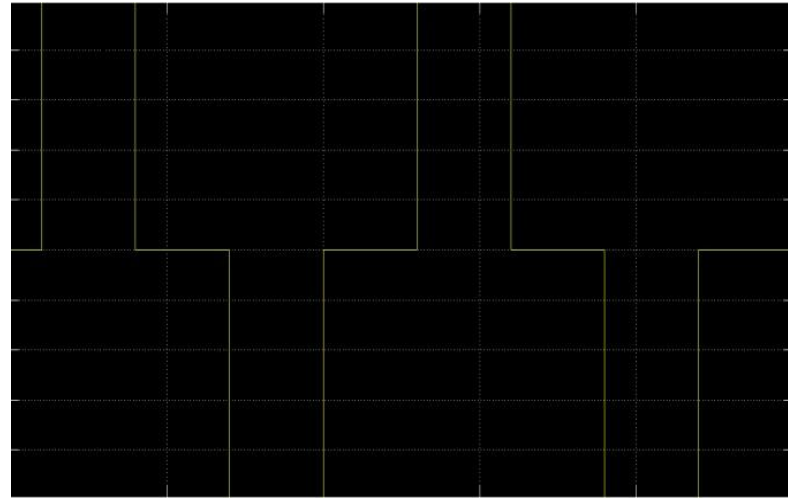

Fig 4.Waveform of 2nd $\mathrm{H}$-bridge inverter

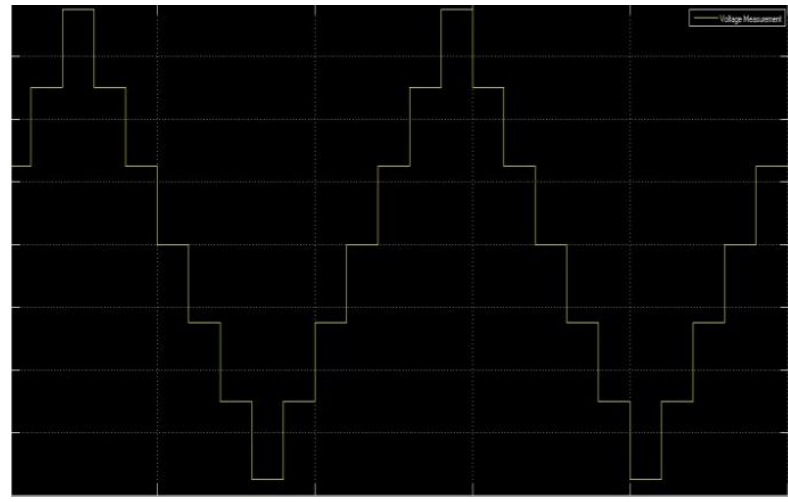

Fig 5.Waveform of this H-bridge inverterconnected in series

\section{SIMULATION}

We created 3-phase inverter using 24 Mosfets, 8 per phase each phase was fired at 120 degree phase shift from the previous one thus creating 3-phase system, we used Simulink (matlab) for the simulation.

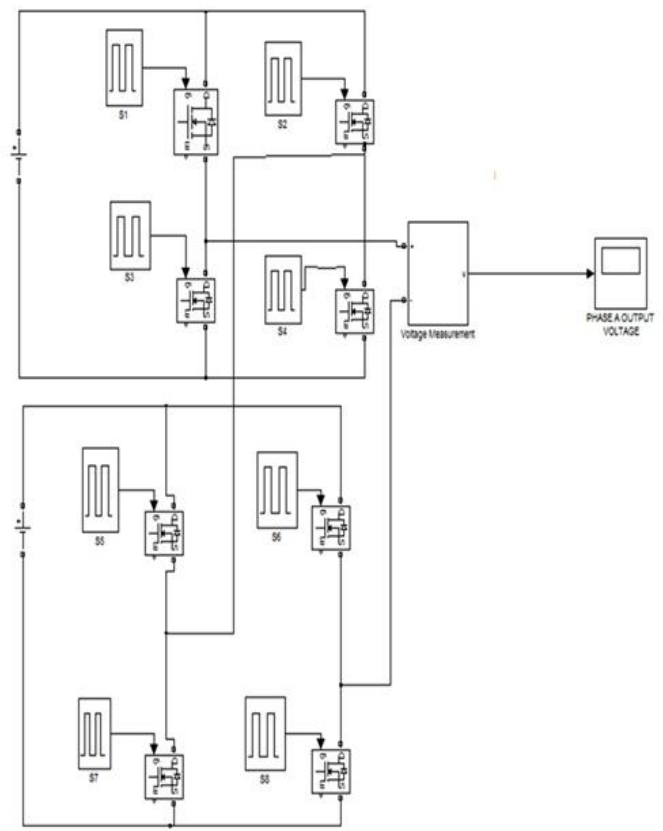

Fig 6.Single Phase Inverter 


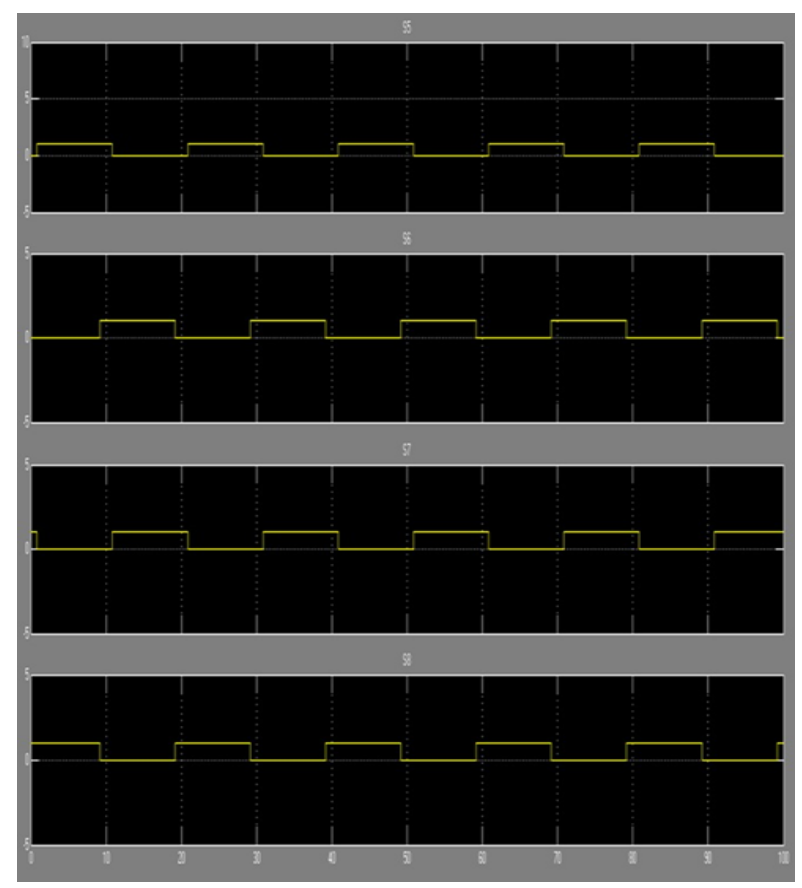

Fig 7: Gate Pules for switches 1-4

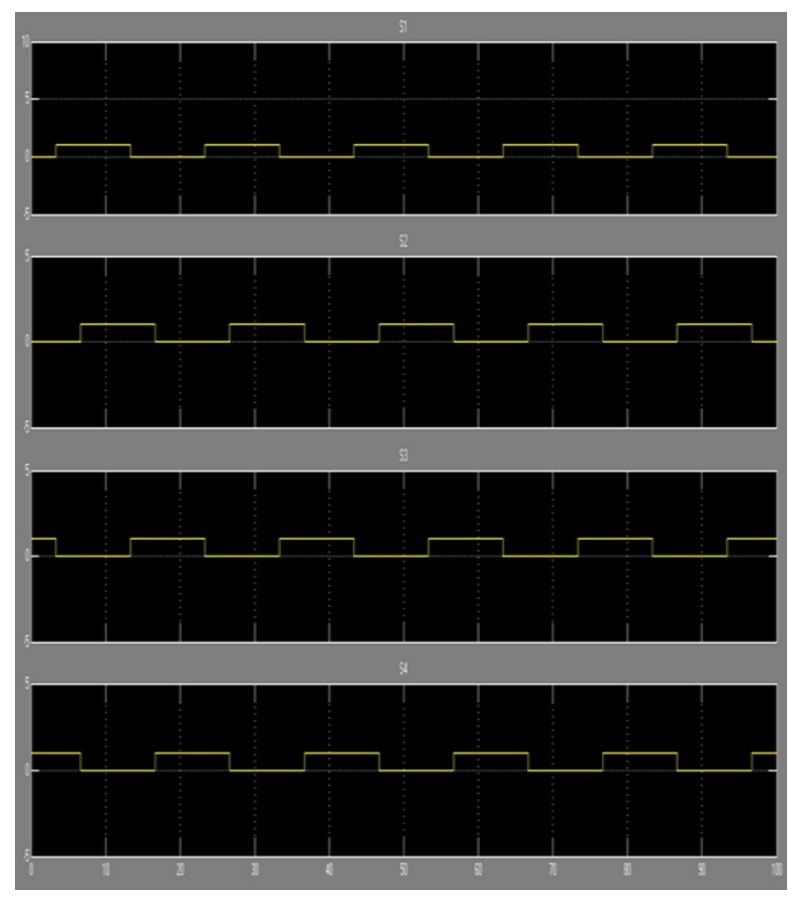

Fig 8: Gate Pulses for switches 5-8

Table1: Timing Interval

\begin{tabular}{|l|l|l|l|l|l|l|l|l|}
\hline $\begin{array}{l}\text { Switch/ } \\
\text { Time- } \\
\text { Interval }\end{array}$ & S1 & S2 & S3 & S4 & S5 & S6 & S7 & S8 \\
\hline $0-.833$ & 0 & 0 & 1 & 1 & 0 & 0 & 1 & 1 \\
\hline $\begin{array}{l}833- \\
3.33\end{array}$ & 0 & 0 & 1 & 1 & 1 & 0 & 0 & 1 \\
\hline $\begin{array}{l}3.33- \\
6.66\end{array}$ & 1 & 0 & 0 & 1 & 1 & 0 & 0 & 1 \\
\hline
\end{tabular}

\begin{tabular}{|l|l|l|l|l|l|l|l|l|}
\hline $\begin{array}{l}6.66- \\
9.16\end{array}$ & 1 & 1 & 0 & 0 & 1 & 0 & 0 & 1 \\
\hline $\begin{array}{l}9.16- \\
10.83\end{array}$ & 1 & 1 & 0 & 0 & 1 & 1 & 0 & 0 \\
\hline $\begin{array}{l}10.83- \\
13.33\end{array}$ & 1 & 1 & 0 & 0 & 0 & 1 & 1 & 0 \\
\hline $\begin{array}{l}13.33- \\
16.66\end{array}$ & 0 & 1 & 0 & 0 & 0 & 1 & 1 & 0 \\
\hline
\end{tabular}

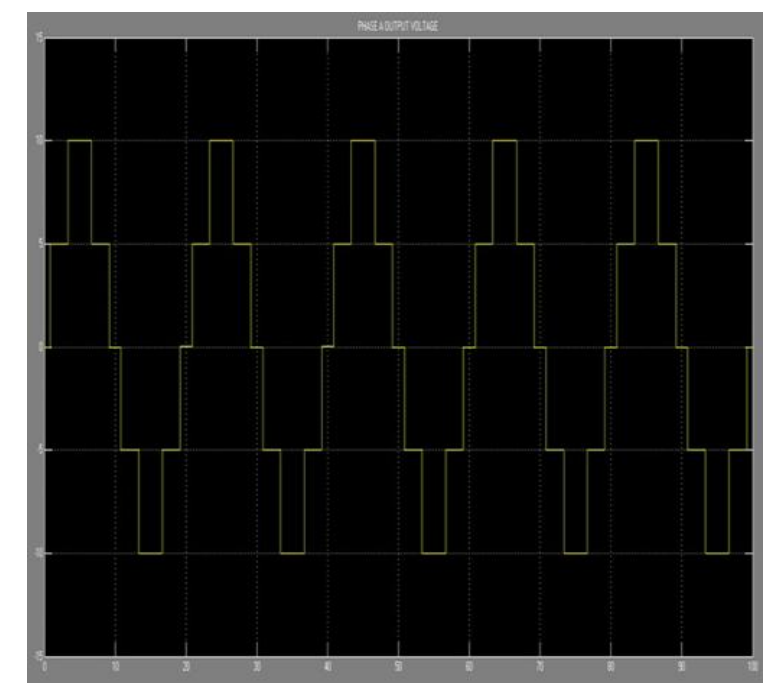

Fig 9:Output of single-phase 5-level inverte

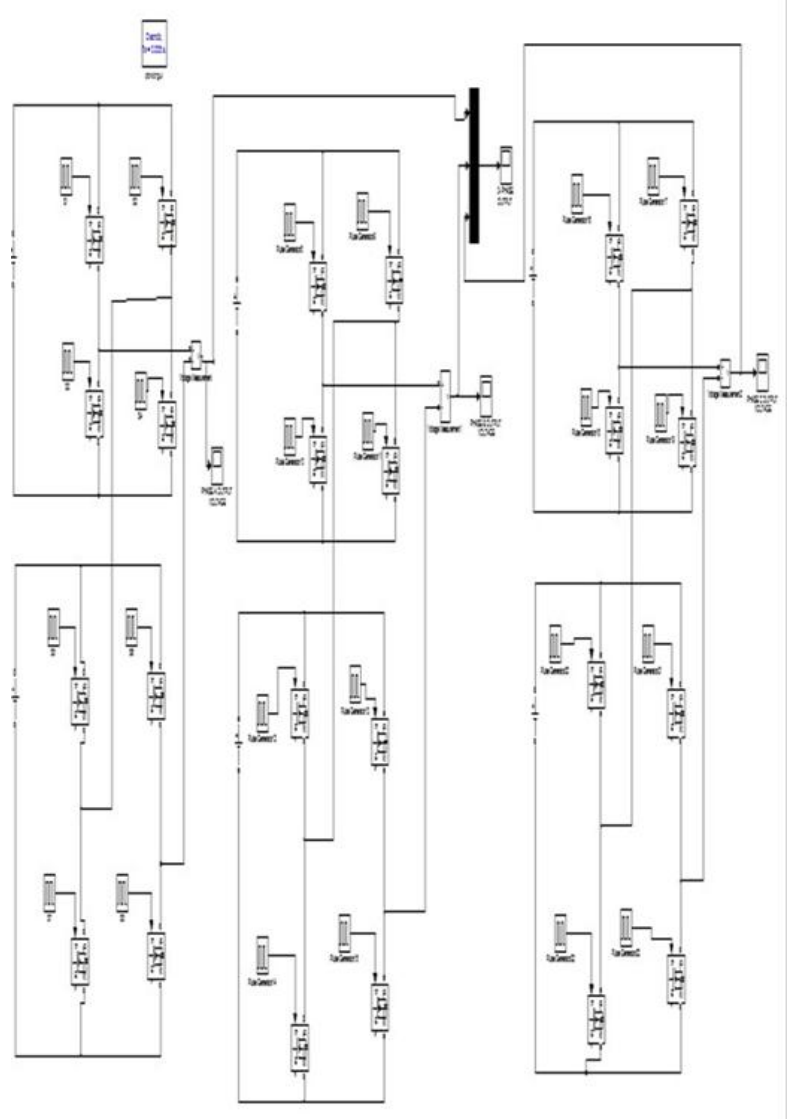

Fig 10: 3- phase 5-level inverter 


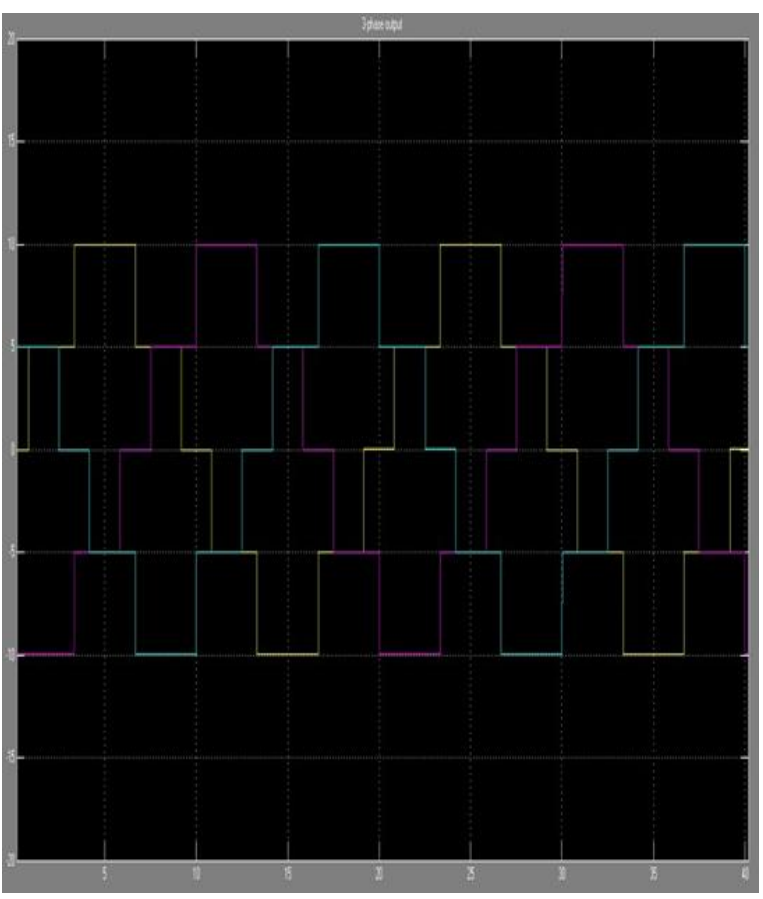

Fig 11:Output of 3- phase 5-level inverter

\section{CONCLUSION}

With this paper our aim was to show the simulation a 3-phase multi-level inverter that we successfully achieved. We used the basic 5-level inverter to simplify the understanding of the reader. We were addressing the problem which was to attain an output which imitated the shape of a sine curve which was not achieved by single $\mathrm{H}$-bridges converter thus the utilization of cascaded H-bridge configuration was used to attain the output successfully and as our output imitates the sine curve it reduces the amount of harmonics present in it. All the simulations are presented in the paper in a very structured manner for the ease of the reader.

\section{APPLICATION}

Cascaded H-bridge multilevel inverter finds its application in motor drives, active filters, electric vehicle drives, DC power source utilization, power factor compensators, back to back frequency link systems, interfacing with renewable energy sources. The series H-bridges make for modularized layout and packaging hence allowing the manufacturing to be done faster and at a cheaper rate.

\section{REFERENCES}

[1] M. Venu Madhav,S. Ravi Kumar," MATLAB based Analysis and Simulation of Multilevel Inverters" International Journal of Computer Applications (0975 8887) Volume 39- No.4, February 2012

[2] Power Electronics circuit,devices and application by Muhammad h.rashid, Professor of Electrical engg. Purdue University

[3] Electronic devices and ciruits theory by RoberL.Boylestead 